\title{
Knowledge of and attitudes towards concussion in cycling: A preliminary study
}

\author{
Howard T Hurst ${ }^{1} \bowtie$, Andrew R Novak ${ }^{2}$, Stephen S Cheung ${ }^{3}$, Stephen Atkins ${ }^{4}$.
}

\begin{abstract}
The aim of this study was to investigate the knowledge of and attitudes towards concussion in cycling. An abbreviated Rosenbaum Concussion Knowledge and attitudes Survey (RoCKAS) was distributed online via social media and completed by 1990 respondents involved in cycling. The RoCKAS comprised separate sections to determine a concussion knowledge index (CKI) providing a score between 0-33, and a concussion attitudes index (CAI) with possible scores between 7-20. Mean scores were $25.9 \pm 11.0$ and $17.7 \pm 3.0$ for CKI and CAI, respectively. However, there remained several concussion knowledge misconceptions and disparity between reported knowledge and attitudes and actions, with $16 \%$ of respondents admitting to riding despite having concussive symptoms and $18.7 \%$ stating they would hide a concussion to stay in an event. The results of this survey indicate those involved with cycling reported reasonable knowledge of concussion symptoms and safe/desirable attitudes towards concussion education. However, despite reporting safe attitudes, the actions of those involved in cycling may be of greater concern, as a considerable number of respondents were still willing to take risks by continuing to cycle knowing they had concussive symptoms.
\end{abstract}

Keywords: Head injuries; survey; bicycling; awareness; prevalence.

$\bigotimes$ Contact email: hthurst@uclan.ac.uk (HT Hurst)

${ }^{1}$ University of Central Lancashire, UK

${ }^{2}$ Rugby Australia, Australia

${ }^{3}$ Brock University, UK

${ }^{4}$ University of Salford, UK

Received: 13 March 2019. Accepted: 24 May 2019.

\section{Introduction}

The dangers of concussion in sport has gained increased awareness, especially in contact sports such as American Football, soccer and rugby (Guskiewicz et al. 2000; Pettersen 2002; Lynall et al. 2016). Despite increased knowledge and management of concussion, many athletes remain unaware that injuries they have sustained may be symptomatic of concussion (Kaut et al. 2003; Valovich-McLeod et al. 2007; Williams et al. 2016). Additionally, athletes frequently do not deem head injuries as severe, leading to an underreporting of concussive injuries (McCrea et al. 2004). Other possible factors associated with underreporting include ability level, gender, not wanting to be removed from practice or game, or not wanting to let teammates down (Register-Mihalik et al. 2013; Sanderson et al. 2016). Along with contact sport athletes, cyclists may also be at risk of incurring head injuries, with crashing being the obvious cause. However, data pertaining to the incidence of injuries in cycling is scarce. Previous studies in road cycling (Decock et al. 2016) and mountain biking (Kronisch et al. 1996) suggest that between $5-13 \%$ of all cycling injuries are diagnosed as concussion. More recently, Becker et al. (2013) reported an overall injury incidence in Downhill Mountain biking of 16.8 injuries per $1000 \mathrm{~h}$ exposure, with a concussive incidence of 0.8 per $1000 \mathrm{~h}$ exposure. However, due to the fact that these studies rely on self-reporting methods to account for injuries, the true number of concussions may differ to those reported.

Mountain bike and BMX cyclists may also risk subconcussive head trauma due to the excessive movement of the rider over irregular terrain. Repeated head accelerations in excess of $82 \mathrm{~g}$ have been reported in these sports, even without direct contact with other athletes or crashing (Hurst et al. 2018a; Hurst et al. 2018b). While it is difficult to define a definitive external 'load' that will result in a concussion, Zhang et al. (2004) proposed that a translational acceleration of the head greater than $82 \mathrm{~g}$ would result in a $50 \%$ change or greater of sustaining a degree of concussion.

The current medical regulations of the world governing body for cycling, the Union Cycliste Internationale (UCI), states 'All those in the presence of a rider and in particular all doctors and paramedical assistants shall be watchful for riders showing symptoms of concussion' (Rule 13.3.061). Rule 13.3.064 stated 'Any rider with a suspected concussion should be immediately removed from the competition or training and urgently assessed medically' (Union Cycliste Internationale 2015).

However, such rules are often difficult to adhere to or enforce in competition, notably road racing, due to riders often being spread out over several kilometres. Riders are unlikely to stop to help a rival competitor in the heat of competition, whilst medical personnel may not be present when an accident occurs. There have been several high-profile examples of such incidences of 
riders continuing to race despite suffering clear impacts to the head. In the 2017 Tour of California, Toms Skujins crashed while descending, staggered and fell again while trying to remount his bicycle. Skujins was then aided by race support personnel in remounting and subsequently weaved wildly across the road for several kilometres before team and race officials finally arrived and removed him from the race. The requirement to complete each stage to continue multi-day stage races such as the Tour of California and the Tour de France possibly contributes to a culture of continuing to race regardless of injuries. Examples of riders continuing to race despite severe injuries include Tyler Hamilton, who raced several stages of the 2003 Tour de France with broken clavicle and more recently Geraint Thomas who completed the 2013 Tour de France having suffered a fractured pelvis early in the race.

Whilst best intent and practice is unquestionably undertaken to protect rider health, there is a notable absence of agreement for the formal identification, monitoring and return to play within professional and amateur cycling concerning head injuries, irrespective of discipline. Underpinning this is the question of effective education and recognition of the aetiology of concussion, allied to awareness of the consequences of immediate and longer-term management of such injuries. Therefore, this preliminary study reviewed the extent of knowledge of concussion symptoms and attitudes towards concussion of those involved in cycling, including athletes, support staff and other stakeholders.

\section{Methods \\ Sample}

The study was a cross-sectional study of 1990 participants, all of whom were involved in cycling in a range of capacities (see Table 1) and took part in an online survey. Approval for the study was granted by the (Approving institutes' name withheld for blind review purposes) STEMH ethics committee (reference number: STEMH 807), in accordance to the ethical standards outlined by Harriss and Atkinson (2011).

\section{Measures}

An amended version of the RoCKAS concussion survey (Rosenbaum and Arnett 2010) was used to assess knowledge and attitudes towards concussion in cycling. As socially desirable answering may have influenced the attitudes section of the questionnaire, Rosenbaum and Arnett (2010) validated the questionnaire against the Marlowe-Crowne Social Desirability Scale. They reported no significant relationship between the two measures $(p>0.05, \mathrm{r}=0.09)$ indicating the RoCKAS was a suitable indicator of attitudes to concussion without contamination by social desirability. In addition, the RoCKAS has a high test-retest reliability (ICC = $0.79, p<0.001)$. With the authors' permission, the questionnaire used in the present study removed questions referring to the original focus towards field sport. Our survey comprised of 4 sections:
Section 1 collected data on respondent demographics and characteristics, and the incidence of concussion (Tables $1 \& 2$ ). Sections 2 and 3 assessed knowledge of concussion via 33 true/false questions to produce a concussion knowledge index score (CKI). These questions were divided into 20 potential symptoms of concussion (section 2) and 13 knowledge statements (section 3) e.g. 'A concussion only occurs if you lose consciousness'. Of the 20 potential symptoms presented in section 2, ten were true and ten false. As with previous studies, these symptoms were based on previous concussion recognition research and the false symptoms presented in section 2 were deemed to be more plausible (e.g. abnormal sense of smell) than those of the original RoCKAS (e.g. hair loss) (Valovich-McLeod 2007; Saunders et al. 2013). For each question in sections 2 and 3 , one point was given for a correct answer and zero for an incorrect answer. This gives a possible CKI score between 0-33.

Section 4 investigated respondents' attitudes towards concussion and subsequent reporting, providing a concussion attitude index score (CAI). Seven statements

Table 1. Participant demographics.

\begin{tabular}{|c|c|}
\hline Characteristic (Total number of respondents) & $\begin{array}{l}\text { N=Frequency } \\
(\%)\end{array}$ \\
\hline \multicolumn{2}{|l|}{ Age $(n=1990)$} \\
\hline Younger than 19 & $205(10.3)$ \\
\hline $20-29$ & $416(20.9)$ \\
\hline $30-39$ & $447(22.5)$ \\
\hline $40-49$ & $414(20.8)$ \\
\hline $50-59$ & $346(17.4)$ \\
\hline Older than 60 & $162(8.1)$ \\
\hline \multicolumn{2}{|l|}{ Gender $(n=1988)$} \\
\hline Male & $1683(84.7)$ \\
\hline Female & $289(14.5)$ \\
\hline Transgender & $10(0.5)$ \\
\hline Other & $2(0.1)$ \\
\hline Prefer not to say & $4(0.2)$ \\
\hline \multicolumn{2}{|l|}{ Current Role $(n=1984)$} \\
\hline Athlete & $1478(74.5)$ \\
\hline Coach/Trainer & $60(3.0)$ \\
\hline Manager/Team Director & $11(0.6)$ \\
\hline Medical personnel & $64(3.2)$ \\
\hline Other & $371(18.7)$ \\
\hline \multicolumn{2}{|l|}{ Primary cycling discipline $(n=1989)$} \\
\hline Road & $1380(69.4)$ \\
\hline Track & $23(1.2)$ \\
\hline Cyclocross & $74(3.7)$ \\
\hline MTB (Cross-country) & $74(9.9)$ \\
\hline MTB (Downhill) & $93(4.7)$ \\
\hline Triathlon & $175(8.8)$ \\
\hline BMX & $22(1.1)$ \\
\hline None & $25(1.2)$ \\
\hline \multicolumn{2}{|l|}{ Years cycling experience $(n=1985)$} \\
\hline Less than 5 yrs & $517(26.0)$ \\
\hline 5 to $10 \mathrm{yrs}$ & $533(26.9)$ \\
\hline More than $10 \mathrm{yrs}$ & $935(47.1)$ \\
\hline \multicolumn{2}{|l|}{ Current race category $(n=1987)$} \\
\hline Novice & $176(8.8)$ \\
\hline Juniors & $105(5.3)$ \\
\hline Seniors & $215(10.8)$ \\
\hline Masters & $364(18.3)$ \\
\hline Veterans & $91(4.6)$ \\
\hline Elite/Professional & $101(5.1)$ \\
\hline I don't race & $935(47.1)$ \\
\hline
\end{tabular}


were presented requiring either: 1) a Yes/No response; 2) an 'Unlikely', 'Neither unlikely or likely' or 'likely' response; or 3) 'Disagree', 'Neither disagree or agree' or 'agree' response. Points were awarded for each statement. For the Yes/No responses, 1 point was awarded for what was considered the least safe/desirable response and 2 points were awarded for safest/most desirable response. For all other statements where there were three optional responses scores of 1, 2 and 3 were given, again with the least desirable response getting 1 point and the most desirable getting 3 points. Therefore, a CAI score ranging between 7-20 was possible. The RoCKAS survey was recreated using SurveyMonkey.com (San Mateo, California, USA) and promoted via social media outlets such as Twitter and Facebook. All respondent data were anonymised.

\section{Analysis}

Descriptive statistics were generated to assess respondents' knowledge and attitudes. Mean \pm SD for CKI and CAI scores are presented along with the frequency and percentage of respondents who answered correctly or selected what was deemed as the safest/desirable answers. Survey data were exported to Excel 2016 (Microsoft Corp., Redmond, USA) for analysis.

\section{Results}

The 1990 respondents came from all global regions: 664 from North America, 24 from South America, 893 from Europe (including Russia), 48 from Asia, 179 from Oceania and 45 from Africa. 137 participants did not disclose their country. Participant demographic data are presented in Table 1, with respondent numbers for each question in parentheses. Table 2 presents descriptive data on the incidence of concussion in cycling and whether respondents missed training as a result.

Mean score for the CKI was $25.9 \pm 11.0$ out of 33 . With respect to concussion knowledge, the symptom questions correctly identified most commonly were 'confusion' (true; 98.6\%), 'dizziness' (true; 97.9\%) and 'headache' (true; 97.3\%), whilst the general concussion knowledge questions most commonly identified correctly were 'a concussion only occurs if you lose consciousness' (false; 98.5\%), 'there is an increased risk of further injury by returning to sporting activity while still experiencing possible concussion symptoms, (true; 97.4\%) and 'symptoms of a concussion can last for several weeks' (true; 96.9\%). Conversely, the symptom questions most commonly identified incorrectly were 'sharp burning pain in neck' (true; 39.9\%), 'weakness in neck movement' (false; $42.5 \%$ ) and 'abnormal sense of smell' (false; 47.8\%), whilst the most common general knowledge misconceptions were 'after a concussion, brain imaging (CAT Scan, MRI, X-Ray etc.) typically shows visible physical damage to the brain' (false; $44.9 \%$ ) and 'people who have had one concussion are more likely to have another concussion' (true; 72.3\%). Table 3 presents descriptive data for concussion knowledge.

Mean score for the CAI was $17.7 \pm 3$. With respect to attitudes to concussion, the safest/most desirable
Table 2. Incidence and consequence of cycling related concussions.

\begin{tabular}{|c|c|}
\hline Concussion item (Total number of respondents) & $\begin{array}{c}\mathrm{N}=\text { Frequency } \\
(\%)\end{array}$ \\
\hline \multicolumn{2}{|l|}{$\begin{array}{l}\text { Have you ever had a cycling related concussion formally } \\
\text { diagnosed? }(n=1977)\end{array}$} \\
\hline Yes & $526(26.6)$ \\
\hline No & $1451(73.4)$ \\
\hline \multicolumn{2}{|l|}{$\begin{array}{l}\text { Have you ever had a suspected cycling related concussion, but } \\
\text { not formally diagnosed? }(\mathrm{n}=1982)\end{array}$} \\
\hline Yes & $629(31.7)$ \\
\hline No & $1353(68.3)$ \\
\hline \multicolumn{2}{|l|}{$\begin{array}{l}\text { Have you ever missed training/racing due to } \\
\text { concussion/suspected concussion? }(n=1984)\end{array}$} \\
\hline Yes & $599(30.2)$ \\
\hline No & $1385(69.8)$ \\
\hline \multicolumn{2}{|l|}{$\begin{array}{l}\text { Have you ever received education about the risks associated } \\
\text { with concussion? }(n=1984)\end{array}$} \\
\hline Yes & $667(33.6)$ \\
\hline No & $1317(66.4)$ \\
\hline \multicolumn{2}{|l|}{$\begin{array}{l}\text { Have you ever had a cycling related concussion formally } \\
\text { diagnosed? }(n=1977)\end{array}$} \\
\hline Yes & $526(26.6)$ \\
\hline No & $1451(73.4)$ \\
\hline \multicolumn{2}{|l|}{$\begin{array}{l}\text { Have you ever had a suspected cycling related concussion, but } \\
\text { not formally diagnosed? }(\mathrm{n}=1982)\end{array}$} \\
\hline Yes & $629(31.7)$ \\
\hline No & $1353(68.3)$ \\
\hline \multicolumn{2}{|l|}{$\begin{array}{l}\text { Have you ever missed training/racing due to } \\
\text { concussion/suspected concussion? }(\mathrm{n}=1984)\end{array}$} \\
\hline Yes & $599(30.2)$ \\
\hline No & $1385(69.8)$ \\
\hline \multicolumn{2}{|l|}{$\begin{array}{l}\text { Have you ever received education about the risks associated } \\
\text { with concussion? }(n=1984)\end{array}$} \\
\hline Yes & $667(33.6)$ \\
\hline No & $1317(66.4)$ \\
\hline \multicolumn{2}{|l|}{$\begin{array}{l}\text { Have you ever had a cycling related concussion formally } \\
\text { diagnosed? }(n=1977)\end{array}$} \\
\hline Yes & $526(26.6)$ \\
\hline No & $1451(73.4)$ \\
\hline \multicolumn{2}{|l|}{$\begin{array}{l}\text { Have you ever had a suspected cycling related concussion, but } \\
\text { not formally diagnosed? }(n=1982)\end{array}$} \\
\hline Yes & $629(31.7)$ \\
\hline No & $1353(68.3)$ \\
\hline \multicolumn{2}{|l|}{$\begin{array}{l}\text { Have you ever missed training/racing due to } \\
\text { concussion/suspected concussion? }(n=1984)\end{array}$} \\
\hline Yes & $599(30.2)$ \\
\hline No & $1385(69.8)$ \\
\hline \multicolumn{2}{|l|}{$\begin{array}{l}\text { Have you ever received education about the risks associated } \\
\text { with concussion? }(n=1984)\end{array}$} \\
\hline Yes & $667(33.6)$ \\
\hline No & $1317(66.4)$ \\
\hline \multicolumn{2}{|l|}{$\begin{array}{l}\text { Have you ever had a cycling related concussion formally } \\
\text { diagnosed? }(n=1977)\end{array}$} \\
\hline Yes & $526(26.6)$ \\
\hline No & $1451(73.4)$ \\
\hline I don't race & $935(47.1)$ \\
\hline
\end{tabular}

attitudes were those relating to the importance of being informed about the signs and symptoms of concussion (agreed; 98.5\%), being informed on how to prevent concussions (agreed; 97.2\%) and the importance of not participating in events when experiencing concussive symptoms (agreed; 91.8\%). The least desirable/riskiest attitudes related to whether respondents continued to participate in cycle events despite experiencing a concussion (yes; 16.3\%) and the likelihood of whether they would hide a concussion to stay in a race/event (likely; 18.7\%). Table 4 provides a summary of respondents' attitudes to concussion and concussion reporting.

\section{Discussion}


This study sought to identify the extent of concussion symptom knowledge and attitudes by those involved in cycling. The key findings were that whilst knowledge of concussion was generally evident, disparities existed between knowledge and attitudes towards managing concussion or concussion-related incidents.

The concussion knowledge index data suggest that knowledge of symptoms within the cycling community is no worse than that revealed for other sports and the general population (Broglio et al. 2010; Weber and Edwards 2012; Register-Mihalik et al. 2013), and in some cases greater than other sports (Williams et al. 2016; Gallagher and Falvey 2017; Viljoen et al. 2017). Results for the CKI in the present study (78.5\%) were higher than those previously reported in English professional football players $(65.6 \%)$ (Williams et al. 2016) and Irish amateur and semi-professional football players (74.8\%) (Gallagher and Falvey 2017). The CKI scores in the present study were also higher than those for amateur South African rugby players (65.9\%), who were assessed using the student version of the RoCKAS (RoCKAS-ST) (Viljoen et al. 2017). However, CKI was lower than that reported for NCAA ice hockey players when using the same RoCKAS-ST questionnaire (range 80-84\%) (Kroshus et al. 2014). Small modifications of the original RoCKAS questionnaire, designed with cycling in mind, should be considered when comparing with results from other sports.

The CKI scores are somewhat reassuring. When compared to other sports, those involved in cycling appear to be more knowledgeable of the signs and symptoms of concussion, though some misconceptions were still evident. With respect to neck symptoms, more than $60 \%$ of respondents incorrectly identified that burning pain in the neck was a true symptom of concussion, whilst more than half $(57.5 \%)$ thought weakness in the neck was also a true symptom. However, the lack of knowledge pertaining to neck pain may, in part, be influenced by changes in 'red flag' indicators on the most recently updated Sport Concussion Assessment Tool questionnaire, 5th Edition (SCAT5), which states that neck pain is a symptom of concussion, whereas the previous iteration of the questionnaire did not (Echemendia et al. 2017). Whilst the current SCAT5 does not identify neck weakness as a symptom of concussion (this question on the RoCKAS survey is one of the 'false' but plausible symptoms made up by Rosenbaum and Arnett (2010)), several studies have found that strengthening the neck may serve as an effective means of reducing impulsive forces to the brain by helping to brace the head and torso and therefore limiting the potential for concussion (Viano et al. 2007; Eckner et al. 2014; Hurst et al. 2018b). Other common misconceptions related to abnormal sense of smell and taste, bleeding from the ear and nose, and joint stiffness and numbness of the arms, with between $34.4 \%$ and $52.2 \%$ of respondents identifying these incorrectly. However, whilst it could be argued that most respondents to the current survey had evident knowledge of concussion, there does remains a number of misconceptions that could be addressed, notably via the implementation of specific concussion education programmes.

Table 3. Frequency of correct responses to knowledge of concussion symptoms.

\begin{tabular}{|c|c|}
\hline Concussion symptoms ${ }^{a, b}$ & $\begin{array}{l}\mathrm{N}=\text { Frequency } \\
(\%)\end{array}$ \\
\hline \multicolumn{2}{|l|}{$\begin{array}{l}\text { Please indicate whether you think the following signs and } \\
\text { symptoms of concussion are 'True' or 'False'. }\end{array}$} \\
\hline Abnormal sense of smell [false] (1824) & $872(47.8)$ \\
\hline Abnormal sense of taste [false] (1824) & $878(48.1)$ \\
\hline Amnesia [true] (1826) & $1711(93.7)$ \\
\hline Joint stiffness [false] (1815) & $1190(65.6)$ \\
\hline Blurred vision [true] (1827) & $1763(96.5)$ \\
\hline Black eye [false] (1802) & $1212(67.3)$ \\
\hline Bleeding from the ear [false] (1817) & $880(48.4)$ \\
\hline Bleeding from the mouth [false] (1812) & $1432(79.0)$ \\
\hline Bleeding from the nose [false] (1813) & $1012(55.8)$ \\
\hline Confusion [true] (1825) & $1800(98.6)$ \\
\hline Fever [false] (1815) & $1238(68.2)$ \\
\hline Dizziness [true] (1827) & $1788(97.9)$ \\
\hline Headache [true] (1831) & $1782(97.32)$ \\
\hline Insomnia [true] (1819) & $1333(73.3)$ \\
\hline Loss of consciousness [true] (1830) & $1688(92.2)$ \\
\hline Nausea or vomiting [true] (1825) & $1686(92.4)$ \\
\hline Numbness or tingling of the arms [true] (1817) & $976(53.7)$ \\
\hline Skin rash [false] (1807) & $1709(94.6)$ \\
\hline Sharp burning pain in neck [true] (1812) & $722(39.9)$ \\
\hline Weakness in neck movement [false] (1817) & $772(42.5)$ \\
\hline \multicolumn{2}{|l|}{ General Knowledge } \\
\hline \multicolumn{2}{|l|}{$\begin{array}{l}\text { Please read the following statements and tick TRUE or FALSE } \\
\text { for each question. }\end{array}$} \\
\hline $\begin{array}{l}\text { There is a possible risk of death if a second concussion } \\
\text { occurs before the first one has healed. [true] (1827) }\end{array}$ & $1581(86.5)$ \\
\hline $\begin{array}{l}\text { People who have had one concussion are more likely to } \\
\text { have another concussion. [true] (1825) }\end{array}$ & $1319(72.3)$ \\
\hline $\begin{array}{l}\text { A concussion only occurs if you lose consciousness. } \\
\text { [false] (1823) }\end{array}$ & $1796(98.5)$ \\
\hline $\begin{array}{l}\text { A concussion only occurs if there is a direct hit to the head. } \\
\text { [false] (1830) }\end{array}$ & $1565(85.5)$ \\
\hline $\begin{array}{l}\text { Being knocked unconscious always causes permanent } \\
\text { brain damage. [false] (1829) }\end{array}$ & 1497 (81.9) \\
\hline $\begin{array}{l}\text { Symptoms of a concussion can last for several weeks. } \\
\text { [true] (1826) }\end{array}$ & 1770 (96.9) \\
\hline $\begin{array}{l}\text { Sometimes a second concussion can help a person } \\
\text { remember things that were forgotten after the first } \\
\text { concussion. [false] (1820) }\end{array}$ & $1584(87.0)$ \\
\hline $\begin{array}{l}\text { After a concussion, brain imaging (CAT Scan, MRI, X-Ray } \\
\text { etc.) typically shows visible physical damage to the brain } \\
\text { (e.g. bruise, blood clots etc.). [false] (1824) }\end{array}$ & $819(44.9)$ \\
\hline $\begin{array}{l}\text { If you have a concussion and not had one previously, you } \\
\text { will become less intelligent. [false] (1824) }\end{array}$ & $1751(96.0)$ \\
\hline $\begin{array}{l}\text { Concussion can sometimes cause emotional disruptions. } \\
\text { [true] (1826) }\end{array}$ & $1700(93.1)$ \\
\hline $\begin{array}{l}\text { There is little risk to long-term health and well-being from } \\
\text { multiple concussions. [false] (1823) }\end{array}$ & $1578(86.6)$ \\
\hline $\begin{array}{l}\text { There is little risk of returning to sporting activity while still } \\
\text { experiencing possible concussion symptoms. [false] } \\
\text { (1825) }\end{array}$ & $1671(91.6)$ \\
\hline $\begin{array}{l}\text { There is an increased risk of further injury by returning to } \\
\text { sporting activity while still experiencing possible } \\
\text { concussion symptoms. [true] (1829) }\end{array}$ & $1782(97.4)$ \\
\hline
\end{tabular}


Table 4. Attitudes to concussion.

\begin{tabular}{|c|c|c|c|}
\hline \multirow[t]{2}{*}{ Attitude to concussion questions } & \multicolumn{2}{|c|}{ Frequency $(\%)^{a}$} & \\
\hline & No & Yes & \\
\hline \multirow{2}{*}{$\begin{array}{l}\text { Have you ever experienced symptoms of a concussion during a cycling } \\
\text { race/event but continued to take part? }\end{array}$} & $1491(83.7)$ & $291(16.3)$ & \\
\hline & Unlikely & $\begin{array}{l}\text { Neither unlikely } \\
\text { or likely }\end{array}$ & Likely \\
\hline $\begin{array}{l}\text { If you had a concussion, how likely would you be to report symptoms to your } \\
\text { team manager, coach or medical personnel? }\end{array}$ & $75(4.2)$ & $230(12.9)$ & $1480(82.9)$ \\
\hline $\begin{array}{l}\text { If you had a concussion, how likely would you be to report symptoms to a } \\
\text { teammate? }\end{array}$ & $69(3.9)$ & $277(15.5)$ & $1437(80.6)$ \\
\hline \multirow{2}{*}{$\begin{array}{l}\text { If you had a concussion during a race/event, how likely would you be to hide } \\
\text { the concussion to stay in a race/event? }\end{array}$} & $1061(59.4)$ & $390(21.9)$ & $333(18.7)$ \\
\hline & Disagree & $\begin{array}{l}\text { Neither disagree } \\
\text { or agree }\end{array}$ & Agree \\
\hline $\begin{array}{l}\text { It is important not to participate in cycling activity when experiencing signs and } \\
\text { symptoms of concussion. }\end{array}$ & $51(2.8)$ & $96(5.4)$ & $1642(91.8)$ \\
\hline It is important to be informed about the signs and symptoms of concussion. & $3(0.2)$ & $24(1.3)$ & $1763(98.5)$ \\
\hline \multirow[t]{2}{*}{ It is important to be informed about how concussions can be prevented. } & $5(0.3)$ & $45(2.5)$ & $1739(97.2)$ \\
\hline & No & & \\
\hline
\end{tabular}

Previous research on English footballers identified insomnia (52\%), amnesia (52\%) and nausea $(36 \%)$ as the most commonly missed true symptoms of concussion (Williams et al. 2016), which was comparable to other studies (Broglio et al. 2010; Register-Mihalik et al. 2013; Saunders et al. 2013). However, respondents in the present study identified these more accurately (insomnia 73.3\%; amnesia 93.7\%; and nausea $92.4 \%$, respectively). Concerning general knowledge of concussion, respondents correctly identified most of the true and false statements, with correct responses exceeding $81 \%$. However, $27.7 \%$ did not believe that following one concussive incidence, people are more likely to sustain another concussion, despite research showing this to be true (Guskiewicz et al. 2000)

The present study also highlighted a disparity between attitudes and actions. When questioned about the importance of concussion education, over $97 \%$ of respondents stated they agreed this was important. Similarly, when questioned whether they agreed or not that it is important not to participate in cycling when experiencing symptoms of concussion, almost $92 \%$ said they agreed, whilst more than $80 \%$ also stated they were likely to report a concussion to team staff and medical personnel or a teammate. However, despite the high percentage of safe/desirable attitude responses, just over $16 \%$ of respondents still stated they had continued to cycle despite suffering from concussive symptoms.

Whilst the majority of respondents stated they would report a concussion, $18.7 \%$ still stated they were likely to hide it to stay in an event, whilst $21.9 \%$ stated they were neither likely or unlikely to hide it. This indecision may be influenced by the importance of a given event as to whether they would or would not hide a concussion. In higher priority events these respondents may select not to report. This assumption is supported by research in football, where $96 \%$ of players interviewed indicated that match importance influenced their decision to play or not despite a concussion (Football IFOA 2013). Additionally, riders may not want to appear weak and rather be perceived as having an alpha personality, therefore may be more likely to hide a concussion. This attitude/perception has previously been reported in American Football players (Anderson et al. 2012) and both male and female athletes (Sanderson et al. 2016). Therefore, the present study would appear to agree with previous research into concussion in sport, in that knowledge of symptoms may not be the major problem (Chrisman et al. 2013; Register-Mihalik et al. 2013; Frass et al. 2014). Instead, the disparity between knowledge, attitudes and actions may be of primary concern.

As with previous concussion surveys, a limitation of the present study may be that respondents were asked to self-report concussive incidences. However, despite the anonymous nature of the survey, some riders may still have been unwilling to state if they had suffered a concussion for the reasons outlined above. Additionally, some riders may not have been aware they had previously suffered a concussion. Therefore, the number of actual concussions may differ to that reported.

\section{Conclusions}

The results of this survey highlight that those involved in cycling are at least similar, if not better educated on the signs and symptoms of concussion when compared to other sports. Yet, similar misconceptions relating to concussive symptoms also exist in cycling when compared to other sports. These findings indicate the need for targeted concussion education, as despite being somewhat knowledgeable on the signs of concussion, many riders are still prepared to compete despite suspected head injuries. The reasons for the disparity 
between knowledge and attitudes remain to be determined. Therefore, mechanisms to affect changes in attitudes need to be developed and implemented within cycling.

\section{Practical applications}

Whilst the findings of this study are encouraging with respect to concussion knowledge within cycling, it was evident that some gaps in knowledge still exist. Athletes appear prepared to take risks with their health in favour of performance. Therefore, the application of these findings could and should be used to aid the development of specific concussion education programmes to be implemented within club and team environments, and also to engage wider stakeholders such as parents/guardians. Development of such education programmes will hopefully lead to a cultural change within cycling, whereby riders feel more empowered to report concussive injuries without fear of their place on the team, funding implications or appearing weak in what is often seen as a 'macho' environment. Whilst it was beyond the scope of this preliminary study, the authors further seek to identify specifically which sub-groups within the sample data collected are least knowledgeable on concussion and which groups are most likely to take risks despite suffering symptoms of concussion. It is also the aim of future research to establish the level of prior concussion education within these subgroups and therefore aid more targeted education programmes. Beyond education, further research should also focus on the development of agreed monitoring and return to sport protocols that are more specific to cycling activity.

\section{Acknowledgements}

The authors wish to thank all respondents for taking the time to complete the survey and all those who helped promote the survey via social media outlets.

\section{Conflict of Interest}

The authors report no conflict of interest.

\section{Reference}

1. Anderson E. and Kian EM. (2012) Examining media contestation of masculinity and head trauma in the National Football League. Men and Masculinities, 15(2): 152-173.

2. Becker J, Runer A, Neunhäuserer D, Frick N, Resch H. and Moroder P. (2013) A prospective study of downhill mountain biking injuries. British Journal of Sports Medicine, 47: 458462.

3. Broglio SP, Vagnozzi R, Sabin M, Signoretti S, Tavazzi B. and Lazzarino G. (2010) Concussion occurrence and knowledge in Italian football (soccer). Journal of Sports Science and Medicine, 9: 418-430.

4. Chrisman SP, Quitiquit C. and Rivara FP. (2013) Qualitative study of barriers to concussive symptom reporting in high school athletics. Journal of Adolescent Health, 52: 330335.

5. Decock M, De Wilde L, Van den Bossche L, Steyaert A. and Van Tongel A. (2016) Incidence and aetiology of acute injuries during competitive road cycling. British Journal of Sports Medicine, 50: 669-672.

6. Echemendia RJ, Meeuwisse W, McCrory P, et al. (2017) The sport concussion assessment tool $5^{\text {th }}$ edition (SCAT5). British Journal of Sports Medicine, 51: 848-850.

7. Eckner JT, Oh YK, Joshi MS et al. (2014) Effect of neck muscle strength and anticipatory cervical muscle activation on the kinematic response of the head to impulsive loads. American Journal of Sport Medicine, 42(3): 566-576.

8. Football IFOA. Laws of the game 2013/14 (2013) Zurich: Fédération Internationale de Football Association.

9. Fraas MR, Coughlan GF, Hart EC. and McCarthy C. (2014) Concussion history and reporting rates in elite Irish rugby union players. Physical Therapy in Sport, 15(3): 136142.

10. Gallagher C. and Falvey E. (2017) Assessing knowledge and attitudes towards concussion in Irish footballers. British Journal of Sports Medicine ,51: A60-A61.

11. Guskiewicz KM, Weaver NL, Padua DA. and Garrett WE. (2000) Epidemiology of concussion in collegiate and high school football players. The American Journal of Sports Medicine, 28(5): 643-650.

12. Harriss DJ. and Atkinson G. (2011) Update: Ethical Standards in Sport and Exercise Science Research. International Journal of Sports Medicine, 32: 819-821.

13. Hurst HT, Atkins S. and Dickinson DB. (2018a) The magnitude of translational and rotational head accelerations experienced by riders during downhill mountain biking. Journal of Science and Medicine in Sport. doi.org/10.1016/j.jsams.2018.03.007

14. Hurst HT, Rylands L, Atkins S, Enright K. and Roberts S. (2018b) Profiling of translational and rotational head accelerations in youth BMX with and without neck brace. Journal of Science and Medicine in Sport, 21: 262-267.

15. Kaut KP, DePompei R, Kerr J. and Congeni J. (2003) Reports of head injury and symptom knowledge among college athletes: implications for assessment and educational intervention. Clinicl Journal of Sport Medicine, 13(4): 213 221.

16. Kronisch RL, Pfeiffer RP. and Chow TK. (1996) Acute injuries in cross-country and downhill off-road bicycle racing. Medicine and Science in Sport and Exercise, 28(11): 13511355.

17. Kroshus E, Daneshavr DH, Baugh CM, Nowinski CJ. and Cantu RC. (2014) NCAA concussion education in ice hockey: an ineffective mandate. British Journal of Sports Medicine, 48(2): 135-140.

18. Lynall RC, Clark MD, Grand EE, et al. (2016) Head impact biomechanics in women's college soccer. Medicine and Science in Sport and Exercise, 48(9): 1772-1778.

19. McCrea M, Hammeke T, Olsen G, Leo P. and Guskiewicz K. (2004) Unreported concussion in high school football players: implications for prevention. Clinical Journal of Sport Medicine, 14(1): 13-17.

20. Pettersen JA. (2002) Does rugby headgear prevent concussion? Attitudes of Canadian players and coaches. British Journal of Sports Medicine, 36(1): 19-22.

21. Register-Mihalik JK, Guskiewicz KM, McLeod TCV, Valovich McLeod TC, Linnan LA, Mueller FO. and Marshall SW. (2013) Knowledge, attitude and concussion-reporting behaviors among high school athletes: a preliminary study. Journal of Athletic Training, 48(5): 645-653.

22. Rosenbaum AM and Arnett A. (2010) The development of a survey to examine knowledge about and attitudes toward concussion in high school students. Journal of Clinical and Experimental Neuropsychology, 32(1): 44-55.

23. Sanderson J, Weathers M, Snedaker K. and Gramlich K. (2016) "I was able to still do my job on the field and keep 
playing": an investigation of female and male athletes' experiences with (not) reporting concussions. Communication and Sport, 5(3): 267-287.

24. Saunders EA, Burdette GT, Metzler JN, Joyner AB. and Buckley TA. (2013) Knowledge of coaching education students regarding sport-related concussions. Athletic Training and Sports Health Care, 5(1): 11-19.

25. UCI Cycling Regulations (2015) Part 13 Medical Rules, Chapter 5. Union Cycliste International.

26. Valovich McLeod TC, Schwartz C. and Bay RC. (2007) Sport-related concussion misunderstandings among youth coaches. Clinical Journal of Sport Medicine, 17(2): 140-142. 27. Viano DC, Casson IR. and Pellman EJ. (2007) Concussion in professional football: Biomechanics of the struck playerpart 14. European Journal of Neurosurgery, 61(2): 313-27.

28. Viljoen CT, Schoeman M, Brandt C, Patricios J. and van Rooyen C. (2017) Concussion knowledge and attitudes among amateur South African rugby players. South African Journal of Sports Medicine, 29(1): 1-6.

29. Weber M. and Edwards MG. (2012) Sports concussion knowledge in the UK general public. Archives of Clinical Neuropsychology, 27(3): 355-361.

30. Williams JM, Langdon JL, McMillan JL. and Buckley TA. (2016) English professional football players concussion knowledge and attitude. Journal of Sport and Health Science, 5(2): 197-204.

31. Zhang L, Yang KH. and King AI. (2004) A proposed injury threshold for mild traumatic brain injury. Journal of Biomechanical Engineering, 126: 226-236. 